\title{
INVESTIGATION OF EXTERNAL RESPIRATORY FUNCTION AND HEMOSTASIS SYSTEM'S STATUS IN PATIENTS WITH CHRONIC OBSTRUCTIVE LUNG DISEASE WITH CONCOMITANT CHRONIC PANCREATITIS
}

\author{
Yulia Karliychuk ${ }^{1}$, Inna Dudka ${ }^{2}$, Vitaliy Smandych ${ }^{3}$, \\ Taisiia Krasnova ${ }^{4}$, Petro Varkhomiy ${ }^{5}$
}

\begin{abstract}
:
Introduction: It can be assumed that the comorbidity course of chronic obstructive pulmonary disease (COPD) and chronic pancreatitis (CP) can enhance the clinical symptoms of both diseases and lead to frequent relapses of the pathological process due to changes in the proteolysis intensity of high and low molecular weight plasma proteins and the state of the hemocoagulation.

Objective: To establish the features of hemocoagulation and proteolytic hemostasis at COPD with concomitant CP.

Methods: 120 patients with COPD and CP were examined. The function of external respiration, total coagulation potential of blood plasma, the state of enzymatic and non-enzymatic fibrinolysis, total fibrinolytic activity were investigated.

Results: CP contributes to the development of broncho-obstructive syndrome, and the maximum indicators of reduction of FEV1 relative to the proper values are observed in patients with a comorbid course of COPD and CP. Reducing the intensity of collagenolysis in patients of groups 1-2 contributed to the development of diffuse pulmonary fibrosis in response to chronic inflammation. The imbalanced increase in the intensity of proteolysis due to reduced expression of its inhibitors in COPD patients with CP led to progressive destruction of the cell membranes of alveolocytes, acinar epithelium of pancreas and epithelium of the bronchial mucosa, acceleration of their apoptosis and development of desquamation, atrophic changes, metaplasia, and the like. The above factors are active as inducers of inflammation, and the formation of pulmonary fibrosis and fibrosis of the pancreas.

Conclusions: In COPD patients with accompanying CP are an increase in the lysis rate of low and high molecular weight proteins and a decrease in blood collagenolytic activity on the background of a significant imbalance in the activity of plasma proteinase inhibitors. Defined suppression of the activity of the anti-coagulation system factors and enzymatic, Hagemanfactor-dependent fibrinolysis indicates the formation of hypercoagulation syndrome in these patients.
\end{abstract}

UDC Classification: 612.2, DOI: https://doi.org/10.12955/pmp.v1.97

Keywords: Chronic obstructive pulmonary disease, chronic pancreatitis, fibrinolysis, azoalbumin.

\section{Introduction}

Chronic obstructive pulmonary disease (COPD) is currently the fourth leading cause of death in the world but is projected to be the 3rd leading cause of death by 2020. More than 3 million people died of COPD in 2012 accounting for $6 \%$ of all deaths globally. COPD represents an important public health challenge that is both preventable and treatable (GOLD, 2019).

In Ukraine, more than 7.4 million adults suffer from diseases of the bronchial and pulmonary system, while COPD accounts for about 1.2 million cases (Feschenko, 2018). We observe the comorbidity during COPD and chronic pancreatitis (CP) quite often, which is due to the presence of a number of pathogenetic mechanisms of mutual encumbrance (Zhelezniakova, 2016; Khorunzhaia, 2017). It can be assumed that the comorbidity course of COPD and CP can enhance the clinical symptoms of both diseases (Babinets et al., 2019) and lead to frequent relapses of the pathological process due to changes in the proteolysis intensity of high and low molecular weight plasma proteins and the state of the factors of hemostasis hemocoagulation.

Aim

To establish the features of the external respiration function, hemocoagulation (prothrombin time, plasma total fibrinolytic activity, the state of enzymatic and non-enzymatic fibrinolysis in blood

\footnotetext{
${ }^{1}$ Higher State Educational Establishment of Ukraine «Bukovinian State Medical University», Chernivtsi, Ukraine, j.m.karliychuk@gmail.com

${ }^{2}$ Higher State Educational Establishment of Ukraine «Bukovinian State Medical University», Chernivtsi, Ukraine, dudka.inna@bsmu.edu.ua

${ }^{3}$ Higher State Educational Establishment of Ukraine «Bukovinian State Medical University», Chernivtsi, Ukraine, smandych_vitaliy@bsmu.edu.ua

${ }^{4}$ Higher State Educational Establishment of Ukraine «Bukovinian State Medical University», Chernivtsi, Ukraine,2005.mf4.15@bsmu.edu.ua

${ }^{5}$ Higher State Educational Establishment of Ukraine «Bukovinian State Medical University», Chernivtsi, Ukraine, pet.varkh1997@gmail.com
} 
plasma, the Hageman-factor-dependent fibrinolysis, the potential activity of plasminogen, the level of fibrinogen in blood plasma, the activity of antithrombin III and factor XIII) and proteolytic (the intensity of lysis of azoalbumin, azocazein, and collagen) hemostasis in patients with COPD and concomitant $\mathrm{CP}$.

\section{Material and Methods of Investigation}

120 patients were examined, including 30 patients with COPD (GOLD 2, B) with an isolated course (group 1), 30 patients with COPD (GOLD 2, B) with accompanying CP in the acute phase (group 2), and 30 patients with $\mathrm{CP}$ with the isolated course (group 3). The mean age of the patients was $45.2 \pm 4.3$ years. The control group consisted of 30 practically healthy individuals (PHI) of the appropriate age and gender.

To study the function of external respiration (FER), computer spirography was performed on Microlab-3300 spirography device (Sensor-Medics, the Netherlands). To study the recurrence of bronchial patency, inhaled samples with bronchodilators- $\beta$-adrenomimetic (salbutamol) and cholinolytic (ipratropium bromide) were used. The results of the spirography survey were evaluated as a percentage of the required values.

The total coagulation potential of blood (prothrombin time (PTT), thrombin time(TT)), plasma total fibrinolytic activity (TFA), the state of enzymatic (EFA) and non-enzymatic fibrinolysis (NFA) in blood plasma, the Hageman-factor-dependent fibrinolysis (HFDF), the potential activity of plasminogen (PAP), the level of fibrinogen (F) in blood plasma, the activity of antithrombin III (AT III), and the activity of factor XIII were studied using sets of reagents from Danysh LTD (Lviv). Using reagents from the same company, the proteolytic activity of blood was studied using the intensity of lysis of azoalbumin (ILAA), azocazein (ILAC), and collagen (CLA). Statistical processing of the material was carried out using modern methods of variation statistics.

\section{Results of the Investigation}

Spirograph indicators reflecting (FER) of examined patients with COPD (GOLD 2, B) and accompanying $\mathrm{CP}$ are shown in the table 1 . The obtained data from the study of FER speed indicators correspond to the stage of COPD (GOLD 2, B): a decrease in FEV1 within 50-80\% of the proper indicators. At the same time, there is a certain pattern of decreasing FEV1. In particular, in patients with COPD average postbronchodilator (PBD) index FEV1 was $74.2 \%$ of necessary size and differed from the same period in PHI 1.2 times $(\mathrm{p}<0.05)$, in patients with COPD and CP indicator of FER FEV1 was significantly different from the previous and PHI $(1.4$ times, $p<0.05)$ and was at a level of $67.2 \%$ from due values. At the same time, the FEV1 index differed from the PHI by $1.15 \%(\mathrm{p}<0.05)$ in patients with isolated CP (Table 1). Thus, we can make a preliminary conclusion that $\mathrm{CP}$ also contributes to the development of broncho-obstructive syndrome (BOS), and the maximum indicators of reduction of FEV1 relative to the proper values are observed in patients with a comorbid course of COPD and CP.

The results of the VC study in patients with the combined course of COPD and CP indicate a likely decrease in the indicator in patients of group 2 by $1.2 \%(p<0.05)$, while in patients of groups 1 and 3 , the indicator only has a tendency to decrease. As the VC indicator in the whole group changed in the range of $80-90 \%$, the presence of restrictive (restrictive) type of lung failure we exclude these patients, but a statistically significant reduction in VC in CP patients with comorbidity with COPD in comparison with an average of PHI can be explained by the phenomenon of maldigestion syndrome with the symptom of bloating, as a result, a symptom of unilateral diaphragm elevation was observed, and the FER study indicated a restriction of the respiratory area of the alveoli in the basal parts of the lungs.

The analysis of results of studying the 2nd phase of coagulation hemostasis showed that PTT was significantly reduced in all observation groups. The maximum similar decline in the indices was observed in patients of group 2 - by $39.5 \%$ compared to the index in the PHP $(\mathrm{p}<0.05)$ in the absence of intergroup differences; in patients of group 1 PTT decreased by $19.5 \%$ compared with those in PHI; and in patients of group 3 there was a decrease of PTT by 30.9\% (p <0.05) (Table 1). Studying the 3rd phase of coagulation hemostasis considering the content of fibrinogen in the blood suggests that in patients of all observation groups this figure was significantly reduced: in patients of the 1st group by $11.0 \%$, group 3 - by $17.5 \%$, group 2 - by $26.6 \%$ and it was significantly different when compared 
in the intergroup aspect $(\mathrm{p}<0.05)$. Reduction of fibrinogen in the blood of patients with COPD indicates either a lack of synthesis of I factor of blood coagulation in the liver (but the functional state of the liver in patients examined was within normal limits), or the activation of the hemostatic system in response to inflammation, which promotes hypercoagulable state development, formation of parietal microtrombi and involving a significant amount of fibrinogen in the process.

\begin{tabular}{|c|c|c|c|c|}
\hline Indexes & $\begin{array}{l}\text { PHI, } \\
\mathbf{n}=30\end{array}$ & $\begin{array}{c}\text { COPD } \\
\text { (group 1), } \\
\mathbf{n}=30\end{array}$ & $\begin{array}{c}\text { COPD and CP } \\
(\text { group 2), } \\
n=30\end{array}$ & $\begin{array}{c}\text { CP } \\
(\text { group 3) } \\
\mathbf{n}=\mathbf{3 0}\end{array}$ \\
\hline $\begin{array}{l}\text { FEV1 (before inhalation } \\
\text { s.), \% }\end{array}$ & $92.3 \pm 1.64$ & $74.2 \pm 1.15^{*}$ & $\begin{array}{c}67.2 \pm 1.31 \\
* / * *\end{array}$ & $\begin{array}{c}83.7 \pm 1.23 \\
* / * * / * * *\end{array}$ \\
\hline $\mathrm{VC}, \%$ & $90.3 \pm 1.54$ & $88.0 \pm 1.23$ & $\begin{array}{l}82.2 \pm 1.19 \\
* / * *\end{array}$ & $\begin{array}{c}85.2 \pm 1.62 \\
* * / * * *\end{array}$ \\
\hline FEV1 (after inhalation s.), & $95.2 \pm 1.23$ & $84.4 \pm 1.12 *$ & $\begin{array}{c}70.5 \pm 2.28 \\
* / * *\end{array}$ & $\begin{array}{c}86.9 \pm 1.23 \\
* / * * / * * *\end{array}$ \\
\hline CLA, E440/ml $\times h$ & $0.84 \pm 0.016$ & $0.78 \pm 0.003^{*}$ & $\begin{array}{c}0.73 \pm 0.004 \\
* / * *\end{array}$ & $\begin{array}{c}0.99 \pm 0.003 \\
* / * * / * * *\end{array}$ \\
\hline Prothrombin time, $\mathrm{s}$ & $22.1 \pm 0.54$ & $17.8 \pm 0.45^{*}$ & $13.4 \pm 0.084 * / * *$ & $15.2 \pm 0.59 *$ \\
\hline Fibrinogen, g/l & $3.19 \pm 0.179$ & $2.84 \pm 0.029 *$ & $2.35 \pm 0.045 * / * *$ & $2.64 \pm 0.074 * / * *$ \\
\hline Thrombin time, $s$ & $16.9 \pm 0.87$ & $13.3 \pm 0.55^{*}$ & $10.6 \pm 0.79 * / * *$ & $12.2 \pm 0.85^{*}$ \\
\hline ATIII, \% & $95.50 \pm 2.01$ & $79.82 \pm 2.132 *$ & $74.23 \pm 3.257 *$ & $69.63 \pm 3.267 *$ \\
\hline NFA, E440/ml/h & $0.48 \pm 0.018$ & $0.60 \pm 0.040^{*}$ & $0.65 \pm 0.009^{*}$ & $\begin{array}{c}0.76 \pm 0.005 \\
* / * * *\end{array}$ \\
\hline EFA, E440/ml/h & $1.20 \pm 0.025$ & $0.87 \pm 0.007^{*}$ & $0.83 \pm 0.012 * / * *$ & $\begin{array}{c}0.61 \pm 0.007 \\
* / * * / * * * /\end{array}$ \\
\hline HFDF, min & $19.4 \pm 0.18$ & $32.2 \pm 2.30 *$ & $33.4 \pm 2.15 *$ & $37.31 \pm 2.31 *$ \\
\hline Factor XIII, \% & $99.90 \pm 3.446$ & $76.85 \pm 4.812 *$ & $72.34 \pm 3.124 *$ & $68.33 \pm 3.692 *$ \\
\hline PAP, min & $18.3 \pm 0.26$ & $22.3 \pm 0.41 *$ & $25.2 \pm 0.38 * / * *$ & $\begin{array}{c}26.1 \pm 0.17 \\
* / * *\end{array}$ \\
\hline
\end{tabular}

Note: $*$ - difference is valid against practically healthy individuals $(\mathrm{p}<0.05) ; * *$ - difference is valid against patients with COPD $(\mathrm{p}<0.05) ; * * *$ - difference is valid against patients with $\operatorname{COPD}$ and $\mathrm{CP}(\mathrm{p}<0.05)$

Source: Author (2018)

The finding of a more pronounced decrease fibrinogen in the blood of patients suffering from COPD with concomitant $\mathrm{CP}$ is indicative of consumption coagulopathy, that is, the use of fibrinogen in the process of intravascular coagulation with simultaneous depletion of the circulating pool of the I factor. While analyzing the blood anticoagulant potential we found a reduction in TT in all groups of patients with the highest percentage of decline in the patients of group 2 - by $37.6 \%(\mathrm{p}<0.05)$ compared with group of PHP, but in the patients of group 1 TT decreased reliably too by $21.8 \%$, in group 3 by $28.2 \%$ with the reliable difference between groups 1, 2 and group 3.

The intensity of plasma proteolysis processes in inflammatory conditions tends to increase in a variety of internal pathology and is controlled by a number of tissue and plasma proteinase inhibitors $(\alpha 2$ macroglobulin, $\alpha 1$-proteinase inhibitor, Antithrombin III, etc.). An imbalance of these systems can lead to a predominance of protein catabolism processes that perform structural (components of cell membranes, coagulation hemostasis) and transport functions that is also a powerful disturbing factor. Analysis of the study results shows that all patients with COPD had an increase in the intensity of lysis of low-molecular proteins $(\mathrm{p}<0.05)$, while in patients of group 1, ILAA exceeded the indicator in the PHI 1.3 times, and in groups 2 and $3-1.6$ times (Figure 1). Maximum activation rates of systemic proteolysis were recorded in COPD patients with concomitant $\mathrm{CP}$, and minimal - in patients with isolated COPD.

That is, the raising of plasma proteolytic activity due to an inflammatory process in the pancreas is a predictor of COPD progression for this comorbidity. In addition, the COPD patients with CP had a more significant increase in the intensity of unrestricted proteolysis of high-molecular-weight proteins (ILAC) $(\mathrm{p} 1-3<0.05)($ Table 1$)$. 
Changes in the intensity of azocol lysis attracted attention: in patients of group 3, the indicator increased relative to the PHI by $1.18 \%(\mathrm{p}<0.05)$, and in groups $1-2$, it decreased by $1.08 \%, 1.15 \%$, respectively, $(\mathrm{p} 1-3<0.05)$ with a significant intergroup difference $(\mathrm{p}<0.05)$. Thus, the intensity of proteolytic degradation of collagen in the blood of patients with $\mathrm{CP}$ was significantly higher than in COPD patients and under conditions of comorbidity of COPD with CP. Reduced collagenolysis activity may contribute to the progression of pulmonary fibrosis in COPD patients, as well as to pancreas fibrosis.

Activation of systemic proteolysis in general in patients with $\mathrm{CP}$ on the background of COPD was also confirmed by changes in the activity of one of the factors of the proteinase-inhibitory system - AT III, which activity in group 3 patients was reduced relative to the norm by $27.1 \%$, that is, had a minimum value, while in patients of group 1 , there was a decrease in the activity of at III by $16.4 \%$, and in group 2 - by $22.3 \%$. Reducing the intensity of collagenolysis in patients of groups $1-2$ contributed to the development of diffuse pulmonary fibrosis in response to chronic inflammation. At the same time, an imbalanced increase in the intensity of proteolysis due to reduced expression of its inhibitors in COPD patients with CP led to progressive destruction of the cell membranes of alveolocytes, acinar epithelium of pancreas and epithelium of the bronchial mucosa, acceleration of their apoptosis and development of desquamation, atrophic changes, metaplasia, and the like. The above factors are active as inducers of inflammation, and the formation of pulmonary fibrosis and fibrosis of the pancreas.

The study of the fibrinolytic activity of blood showed that the plasma TFA in patients of all groups was significantly lower than the control indicators: in group 1 - by $12.5 \%$, group 2 - by $11.9 \%$ and group $3-10.0 \%(\mathrm{p} 1-3<0.05)$ (Figure 1$)$ with a significant intergroup difference $(\mathrm{p}<0.05)$.

\section{Figure 1: Intensity of lysis of azoalbumin in patients with chronic obstructive pulmonary} disease and chronic pancreatitis

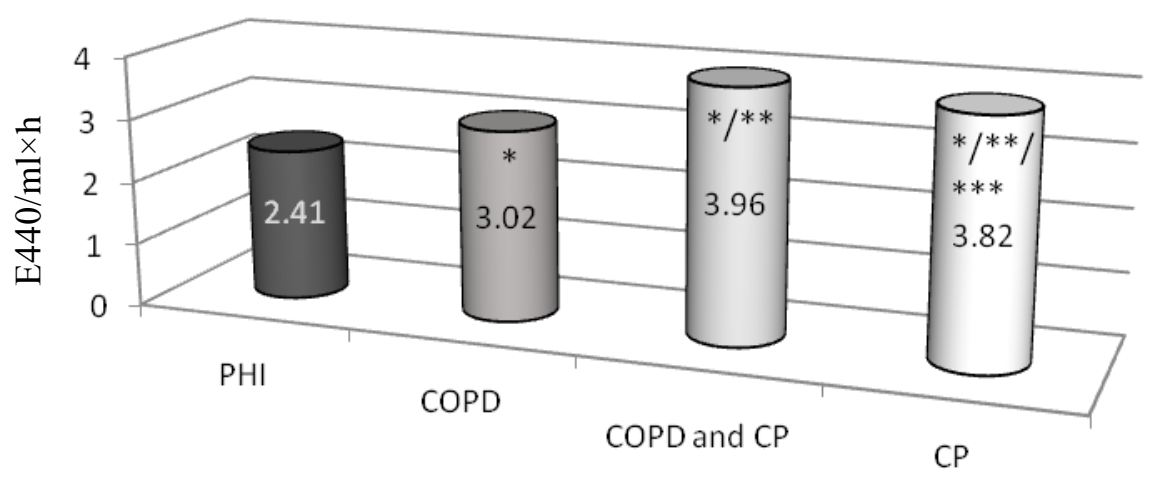

Note: *-difference is valid against practically healthy individuals $(p<0.05) ; * *$-difference is valid against patients with COPD $(p<0.05) ; * * *$-difference is valid against patients with COPD and $C P(p<0.05)$

Source: Author (2018)

TFA inhibition occurred due to a decrease in FFA (p1-3<0.05). At the same time, the NFA in patients of all groups increased compensatory, as evidenced by an increase in the NFA index compared to the PHI group ( $1-3<0.05)$. In addition, there was a significant decrease in the activity of HFDF: in group $1-1.6$ times, in group $2-1.7$ times, in group $3-1.4$ times $(\mathrm{p} 1-3<0.05)$ in comparison with PHI with no significant difference between groups ( $>0.05$ ). The activity of fibrin-stabilizing factor in patients of group 1 decreased by $23.1 \%$, in group $2-27.7 \%$, in group $3-15.7 \%(\mathrm{p} 1-3<0.05)$ that indicates a violation of the post-coagulation phase of blood clotting. In COPD patients with accompanying $\mathrm{CP}$, a significant decrease in PAP was found: in group 1 patients - by $23.9 \%$, in group 2 patients $-40.0 \%$, and in group $3-35.0 \%$, respectively $(\mathrm{p} 1-3<0.05)$. The results of the study of anti-coagulation and fibrinolytic system factors indicate the formation of a hyper-coagulation syndrome in COPD patients with accompanying CP. The consequence of significant activation of hemocoagulation against the background of TFA oppression is local blood clotting in small vessels of the lungs. The main purpose 
of Hageman-factor-dependent fibrinolysis is to "cleanse" the circulatory bed from fibrin clots formed under these conditions. We found a decrease in the rate of Hageman-factor-dependent fibrinolysis that is a likely cause of compensatory activation of NFA. Slowing blood circulation in the lungs due to the formation of blood clots in the microvasculature promotes increased hypoxia and, probably, the formation of reactive oxygen species and free nitrogen radicals with subsequent damage to cell membranes and closure of the "vicious" circle of pathogenesis of COPD and CP progression.

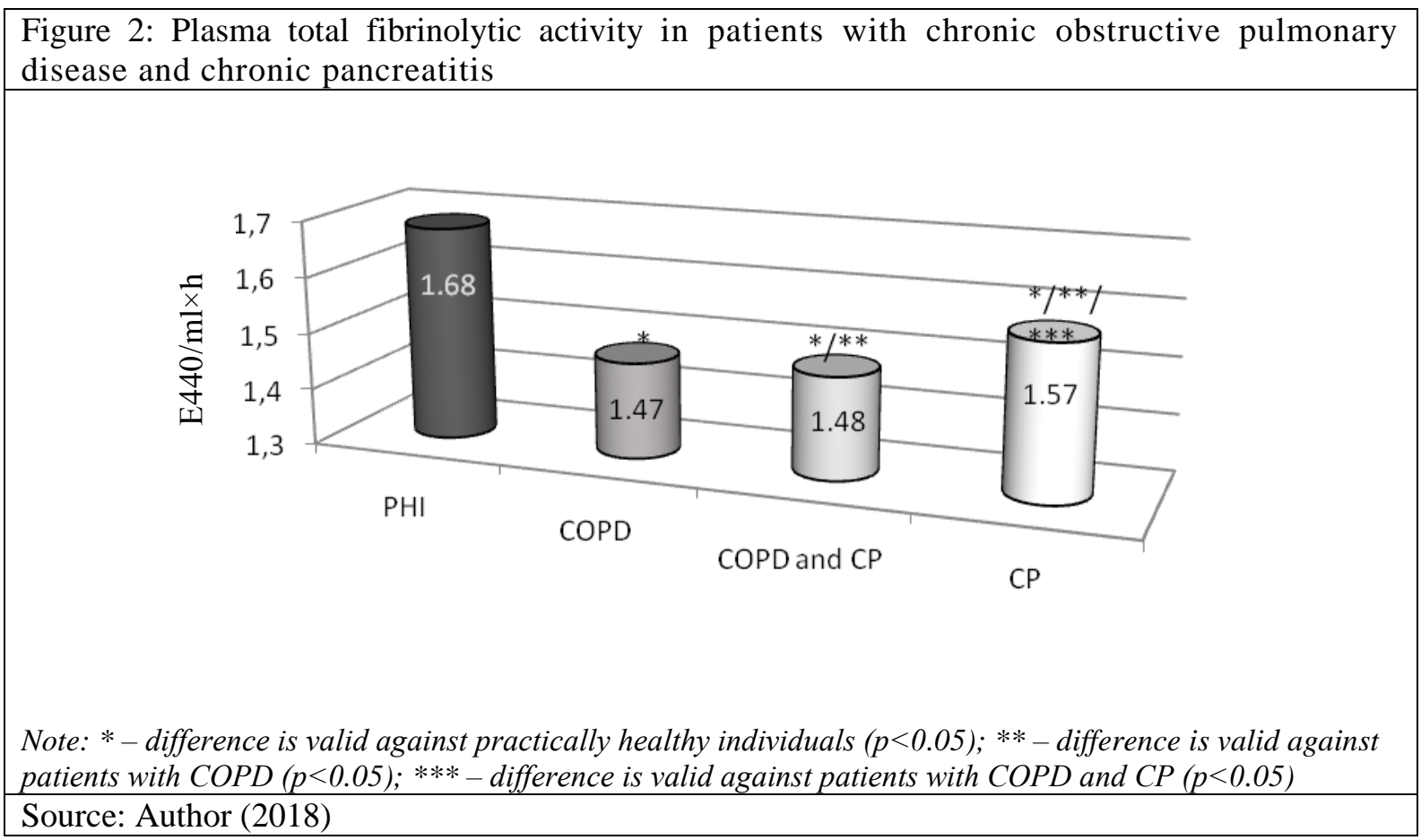

\section{Conclusions}

Features of proteinase-inhibitory system disorders in chronic obstructive pulmonary disease patients with accompanying chronic pancreatitis are an increase in the lysis rate of low and high molecular weight proteins and a decrease in blood collagenolytic activity on the background of a significant imbalance in the activity of plasma proteinase inhibitors. Defined suppression of the activity of the anti-coagulation system factors and enzymatic, Hageman-factor-dependent fibrinolysis indicates the formation of hypercoagulation syndrome in chronic obstructive pulmonary disease patients with accompanying chronic pancreatitis.

\section{References}

Babinets L. S., Protsyuk R. G., Kvasnitska O. S. (2019) Smoking as a factor of immune deficiency deepening in patients with chronic obstructive pulmonary disease and chronic pancreatitis. Likars'ka Sprava [Medical Practice]. 1-2. 17-22. https://doi.org/10.31640/JVD.1-2.2019(3)

Feshchenko YU. I. (2018) Aktual'ni problemy suchasnoyi pul'monolohiyi [Urgent challenges of modern pulmonology]. Ukrayins'kyy pul'monolohichnyy zhurnal [Ukrainian Pulmonology Journal]. 3. 5-12. (In Ukrainian). DOI: 10.31215/23064927-2018-101-3-5-12.

Global Initiative for Chronic Obstructive Lung Disease. Global strategy for the diagnosis, management and prevention of chronic obstructive pulmonary disease 2019 report. https://goldcopd.org/wp-content/uploads/2018/11/GOLD-2019-v1.7FINAL-14Nov2018-WMS.pdf. Accessed March 22, 2019.

Khorunzhaia V.S. (2017) Effektivnost' lecheniya khronicheskogo obstruktivnogo zabolevaniya legkikh v sochetanii s khronicheskim pankreatitom [Effectiveness of treatment of chronic obstructive pulmonary disease in combination with chronic pancreatis]. Simeyna medytsyna [Family Medicine]. 3(71). 130-132. (In Russian).

Zheliezniakova N. M. (2016) Imunolohichni aspekty komorbidnoho perebihu khronichnoho obstruktyvnoho zakhvoryuvannya lehen' ta khronichnoho pankreatytu [Immunological aspects of comorbid course of chronic obstructive pulmonary disease and chronic pancreatitis]. Vestnik kluba pankreatologov [Herald of Pancreatic Club]. 4. 36-39. (In Ukrainian). 